\title{
Research on the Applicability of Financial Management System Based on Computer Erp System
}

\author{
Zhaohua Liu \\ Shandong Vocational College of Science and Technology, Wei fang, Shandong, China,261053
}

\begin{abstract}
In the EPR environment, the financial management system has the characteristics of integrity, scientific decision-making, timeliness of information acquisition and comprehensive information service. However, in the actual financial management process, due to the neglect of practical research, the upgrade and promotion of ERP software are hindered. On the whole, the ERP system is single and the rights and responsibilities are not clear. In order to improve the ERP financial management system, in the process of system design, it is necessary to clarify the system design requirements, clarify the system architecture and clarify the system functions. The realization of the whole ERP financial management system, based on the system development environment and database design, must establish the management model according to the enterprise management practice, strengthen the enterprise training, ensure the safety of information management, clarify the responsibilities of various departments and ensure the normal operation of ERP financial management system.
\end{abstract}

\section{Introduction}

Enterprise resource planning (ERP) is a concept based on the era of network economy, which breaks away from the traditional enterprise financial management mode and establishes a management system with resource supply chain. This concept was first proposed by the American computer technology consulting and evaluation group. At present, ERP management idea has been gradually applied in various fields of enterprise management, the design and function realization of financial management system has been the specific performance of measuring ERP application effect, and also the concentrated embodiment of an enterprise operation effect and work efficiency. For enterprise managers, it is of positive significance to correctly understand the significance of establishing and improving the financial management system in enterprise management to design a reasonable financial management system according to the enterprise management needs and financial operation status, so as to realize the implementation control of enterprise financial and material resources, so as to improve the efficiency and effect of enterprise financial management Enterprises should grasp the first opportunity in the deployment of development strategy ${ }^{[1]}$.

\section{Analysis of the characteristics and deficiencies of ERP financial management system}

\subsection{Characteristics of ERP financial management system}

The financial management system under ERP environment has positive significance for the improvement of enterprise management level, specifically because it has the following basic characteristics: the integrity of financial management, the related software in the system can record the financial information in detail according to the classification of project, Department, personnel and accounting subject according to the actual needs of the enterprise The events occurred in the management ensure the integrity of the enterprise's financial information, and provide unified information support according to the specific needs of the enterprise managers, and provide the information basis for the correct decision-making of the enterprise; the scientificity of the financial decision-making can establish the financial number through the existing financial information, through the purposeful financial accounting and data analysis According to the model, it can correctly predict the future market situation to ensure the scientific financial decision-making; the timeliness of information acquisition and the comprehensiveness of information service; ERP realizes the real-time 
management and unified control of enterprise resource information, and can obtain effective reference information at any time according to the management needs, so as to ensure the timeliness of information and the comprehensiveness of service ${ }^{[2]}$.

\subsection{Lack of ERP financial management system}

The technical basis of ERP financial management system design and operation lies in various ERP software. In the financial management system, we need to choose the appropriate ERP software according to the current situation of the enterprise operation, and with the development of the enterprise and the change of the market, constantly upgrade the system software. However, as far as the current operation status of ERP financial management system is concerned, due to the neglect of practical research in financial management, the upgrading of domestic ERP software is basically in a stagnant state, which indirectly leads to the difficulty in popularizing the research and development achievements of ERP software. At present, the ERP system applied in enterprise management has a single structure and unclear division of rights and responsibilities On the contrary, it affects the efficiency of enterprise management.

\section{Design and analysis of financial management system based on ERP}

\subsection{The design of system requirement}

Based on the requirements of enterprise management, when designing ERP financial management system, the system requirements must be clear. First of all, we must ensure the advanced technology, based on the advanced ERP theory, choose the appropriate network information technology and data processing technology, and realize the integrated management of material resources, capital flow and information resources ${ }^{[3]}$. At the same time, the use of multi-level user rights management system, to ensure the security of information, clear the rights and responsibilities of employees at different levels of management, different levels of management of their information rights, can ensure the normal operation of the enterprise, to ensure enterprise information security. In addition, the system must have the corresponding auxiliary analysis and decision-making function, process the enterprise information systematically, provide intuitive and reliable information for decision-makers, at the same time, it should have query function to provide convenience for employees to query information.

\subsection{The design of systematic structure}

ERP financial management system is composed of several financial management modules, and different modules are linked with a link of actual financial management, which is a way to realize the function of financial management. On the whole, it can be divided into general ledger, financial budget, cash management, cost management modules, subdivided into inventory management, fixed assets management, cost management, accounts receivable, accounts payable and other modules. The realization of system functions is based on the refined management and unified operation of different functional modules ${ }^{[5]}$. The managers of different modules should input the financial operation information of their responsible areas into the system in detail and accurately, so as to realize and improve the efficiency of information management and ensure the authenticity, timeliness and comprehensiveness of information.

\section{The relationship between ERP financial sub module and other sub modules}

According to the classification of accounting, ERP financial management system has many interrelated modules, such as general ledger module, accounts receivable module, accounts payable module, cash management module, cost accounting module, financial statement analysis module, financial budget module, fixed assets module, expense allocation module, etc. see Figure 1 for details. The designer should construct reasonable system module and design scientific and reasonable system framework according to the enterprise's financial management demand and financial operation route, so as to ensure the order and timeliness of financial information resource management, so as to ensure the application effect of ERP financial management system ${ }^{[4]}$. 


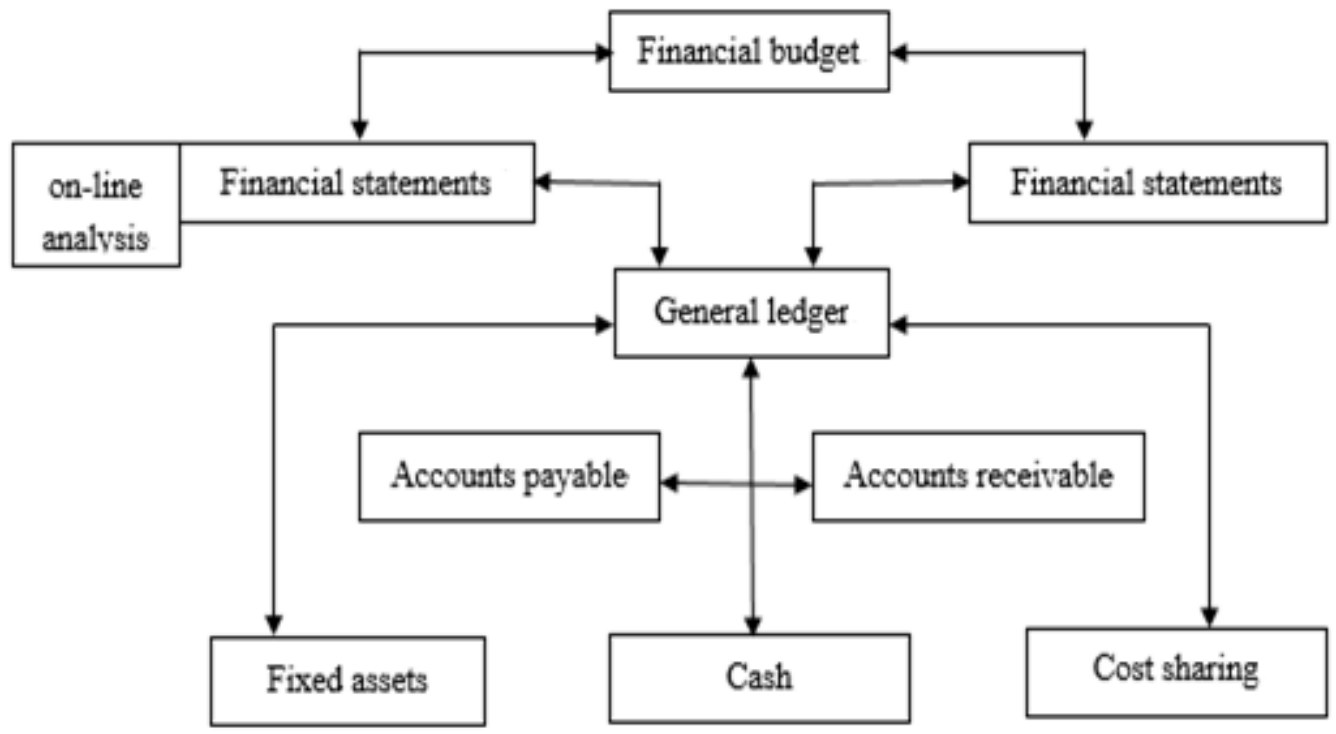

Figure 1. Structure of financial management system.

\subsection{The design of system function}

The financial management of ERP system is the financial management of integrated information. It integrates all the financial activities related to the enterprise, such as purchasing management, raw material management, finished product management, sales management, production management, fixed assets management, etc. Therefore, the biggest difference between ERP and single accounting software in structure is that the former has a higher degree of data integration. The business processed by ERP system basically covers all businesses of the enterprise, and the data of business process comes from various business subsystems. Therefore, ERP financial module and other business modules have a close data exchange relationship, as shown in Figure 2.

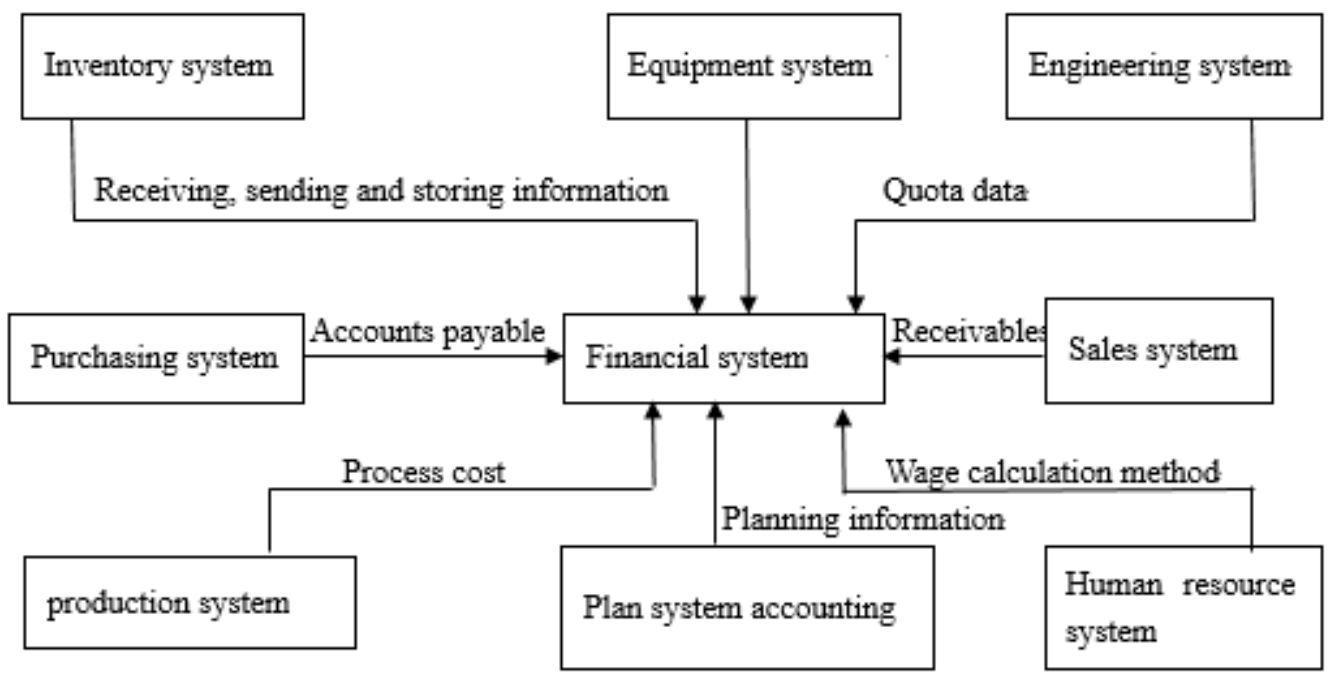

Figure 2. The relationship between financial management system and other subsystems.

\section{Application and function of ERP system in financial management}

\subsection{Application}

The unification of logistics and capital flow in purchase payment cycle. When the purchased materials are put into the warehouse, the material administrator will register according to the purchasing situation. At this time, the ERP system will automatically generate accounting vouchers according to the warehousing data, and update the corresponding accounting subjects, so as to realize the unification of logistics and capital flow in the purchase payment cycle. The unification of logistics and capital flow in production cycle. The production order is the basis for the workshop to get raw materials from the warehouse, which will lead to the decrease of inventory and the increase of production cost. Through the implementation of ERP related operations to generate accounting vouchers, and then post, update the corresponding account data in the general ledger system. 
Through processing raw materials, the production workshop produces products that meet the requirements of customers and stores them in the warehouse. At the same time, it generates accounting vouchers by executing ERP related operations, and then Posts them. In the general ledger module, it reduces the amount of production cost account and increases the amount of inventory account according to the actual situation, so as to realize the unification of logistics and capital flow in the production cycle. The unification of logistics and capital flow in the circulation of sales and collection. After receiving the customer's order, the sales department informs the warehouse to deliver the goods to the customer according to the order, which will lead to the decrease of inventory and the increase of accounts receivable ${ }^{[6]}$. Through the implementation of ERP related operations to generate accounting vouchers, the amount of related accounts receivable and inventory can be updated in the general ledger system after posting. In this way, after receiving the payment from the customer, you can directly perform the relevant operations of ERP, generate the collection voucher and post it, and update the data of cash and accounts receivable in the general ledger system at the same time. So as to realize the unification of logistics and capital flow in the sales and payment cycle.

\subsection{Function}

It improves the comprehensiveness and accuracy of financial information. The collection of financial information is an important module of enterprise financial management, and the powerful data collection and collation function of ERP system can effectively improve the comprehensiveness and accuracy of financial information collection, and provide timely and accurate reference information for enterprise's major decision-making, so as to make enterprise's decisionmaking more scientific. Objective analysis of the data. When anyone makes a decision, they are inevitably subjective to a certain extent, and the leaders of enterprises are no exception. ERP system will analyze and sort out various business conditions through online form, generate scientific data information, provide scientific relevant data for the development plan of enterprises, and reduce the adverse impact of subjective consciousness on enterprise decision-making. Improve the efficiency of enterprise financial management. The timely and accurate information provided by ERP system can greatly improve the work efficiency. The generation mode of financial information reduces the influence of human factors and errors on its correctness, thus reducing the cost of enterprises and realizing the standardization of enterprise financial management, which is of positive significance to the improvement of enterprise comprehensive management level[ ${ }^{[7]}$.

\section{Conclusion}

ERP theory has many effects in the application of enterprise management, especially in the financial management of enterprises, which can help managers master all kinds of basic information and summary information of enterprise operation, correctly predict the financial operation status of enterprises, correctly deal with the ever-changing market, and remain invincible. At present, ERP financial management system has been running in many fields, but there are still some deficiencies in theory and practice. In order to really play the role of ERP theory, we should strengthen the practical research of enterprise finance, carry out the research and development of ERP software according to the actual needs of enterprise operation, and strengthen the promotion of ERP scientific research results And constantly improve its management system.

\section{References}

1. Yang Mingyuan, Liu Yangchen, Zhou Hu. Research on construction and evaluation of financial management system of electric power enterprise based on ERP $[J]$. Chinese and foreign entrepreneurs, 2016, 02:149.

2. Chen Wen. Improvement and Realization of enterprise financial management module based on ERP Environment Instrument. 2016, 05:165-166 + 169.

3. Bai Yun. Design and implementation of ERP electronic financial management and financial information query system under touch screen windna. [J]. Electronic design engineering, 2016, 14:00 155-157.

4. Liang Wenjuan. Research on the construction and evaluation of financial management system of power enterprises based on ERP. Financial circles (Academic Edition), 2016, 18:228-232.

5. Wu Zhilin, Yang Daoguang, Zhu Ying. Reflections on the practical ability training of higher vocational accounting students based on ERP financial management system [J]. Science and technology vision, 2014, 23:29-30.

6. Chen can. Research on ERP system based on financial management [D]. North China Electric Power University, 2013.

7. Chen Xiaoman. Research on the application of ERP system in enterprise financial management [J]. Chinese market, 2013, (46): 97-98. 